\title{
Resenhas
}

\section{QueSTÕES TEÓRICAS E METODOLÓGICAS DA AVALIAÇÃO PSICOLÓGICA}

\author{
Sisto, F. F.; Sbardelini, E. T. C. \& Primi, R. - Orgs. (2001) \\ Contextos e Questões de Avaliação Psicológica. São Paulo: Casa do Psicólogo, 235 págs.
}

\begin{abstract}
A avaliação psicológica é uma importante prática do psicólogo e, por sua vez, vem sendo aplicada em diferentes contextos de atuação profissional. A avaliação não é recente na psicologia, datando do século XIX os primeiros trabalhos significativos que deram início ao desenvolvimento da área. É certo que muitas foram as evoluções percebidas desde a criação do primeiro instrumento até os dias atuais, em contrapartida, muito ainda se tem a desenvolver e a aprimorar. Em relação à realização da prática da avaliação psicológica, sabe-se que diferentes posições teóricas coexistem e é imprescindível que pesquisas e estudos dêem o suporte necessário para o avanço.

O livro aqui resenhado é uma contribuição significativa para a área, tendo sido organizado por Sisto, Sbardelini e Primi, mas contando com a participação de vários autores, na sua maioria membros de um programa de pós-graduação em avaliação psicológica. Os autores procuraram abordar diferentes experiências em relação à avaliação.

A obra é constituída por uma apresentação e por 14 capítulos. A apresentação é escrita pelos três organizadores e, além de versar sobre a área da avaliação psicológica, discutindo a situação atual de pesquisas, e de observar o movimento dos Conselhos Regionais e do Federal de Psicologia na busca de resoluções específicas relacionadas à avaliação, ainda é possível encontrar na apresentação, a descrição dos temas abordados em cada capítulo. Os organizadores alertam que esta tem sido uma das áreas de destaque nas discussões sobre políticas de pesquisa em psicologia. Os capítulos que compõem o livro retratam contextos e questões diversas e não possuem um eixo teórico ou metodológico norteador, referindo-se a experiências clínicas e psicoeducacionais.

Embora não haja um eixo teórico, é possível encontrar uma organização coerente na sequiência dos
\end{abstract}

capítulos. Uma primeira parte de textos destina-se à avaliação psicológica realizada no contexto clínico (capítulos 1, 2, 3, 4 e 5); os capítulos seguintes destinam-se à avaliação realizada no contexto psicoeducacional (capítulos 6, 7 e 8); em seguida, vêm os artigos referentes à construção de instrumentos $(9,10,11 \mathrm{e}$ 12). Os dois últimos trabalhos apesar de diferenciaram-se dos demais por tratarem de temas específicos, tais como o $13^{\circ}$ capítulo que discute a avaliação funcional do comportamento e, o $14^{\circ}$ que problematiza a avaliação das dificuldades de atenção, são muito relevantes para o contexto da avaliação. As referências bibliográficas são apresentadas ao final de cada capítulo.

O primeiro texto intitulado A questão do diagnóstico em psicoterapia breve é de autoria de Rita A. Romaro e tem como objetivo avaliar a eficácia da psicoterapia breve dinâmica, através da utilização da Escala Diagnóstica Adaptativa Operacionalizada (EDAO); a autora utiliza-se de um caso clínico para relacionar o diagnóstico, a modalidade terapêutica e a avaliação dos resultados.

O capítulo seguinte trabalha os Modelos circumplexos da personalidade - O MCMI - II como instrumento para avaliação clínica (capítulo 2) e tem como autor, Sebastián Urquijo. O texto versa sobre a avaliação da personalidade através do Inventário Clínico Multiaxial de Milon - II (MCMI-II), composto por 175 itens distribuídos em 26 escalas, cuja base é a teoria dos padrões de personalidade e a concepção de um contínuo normal-anormal.

Os desafios e as implicações da avaliação dos transtornos de personalidade são discutidos por Sônia Regina Loureiro no capítulo 3 - Transtorno de personalidade e a avaliação psicodiagnóstica. A autora defende que o diagnóstico psicológico torna-se cada vez 
mais necessário e considera imprescindível a utilização de procedimentos sistemáticos de diagnóstico, a fim de se conhecer o indivíduo para que se possa propor uma abordagem terapêutica adequada.

Cláudio Garcia Capitão reflete sobre a violência sexual realizada por pais, no quarto capítulo, nomeado Uma breve avaliação da violência sexual: a vingança do Édipo. Sua apresentação enfoca a relação entre o agressor e o agredido, mais especificamente, a violência sexual de pais em relação aos seus filhos, procurando avaliar as determinações psíquicas do agressor e as seqüelas no psiquismo do agredido.

O quinto capítulo, de autoria de Anna Elisa de Villemor Amaral Güntert (Técnicas Projetivas: o Geral e o Singular em Avaliação Psicológica), compreende as técnicas projetivas como instrumentos que possibilitam atender os indivíduos nas suas particularidades ao mesmo tempo em que, ao processar as informações obtidas, as incorpora num todo teórico passível de generalização.

O capítulo seguinte, de Elizabeth Teresa Brunini Sbardelini, trata de questões relacionadas à orientação profissional. A autora no capítulo Avaliação Psicológica e Orientação Profissional: Contribuições de Teste de Fotos de Profissões - BBT alerta que os contextos do indivíduo (histórico, político, econômico, social) devem ser compreendidos quando da realização do processo de avaliação, para que desta maneira se possa compreender melhor o dinamismo do sujeito.

Em seguida, encontra-se o sétimo capítulo, cuja autora é Maria Cristina Rodrigues Azevedo Joly (Leitura no Contexto Educacional: avaliando estratégias para aquisição de habilidades criativas) que aborda a importância da leitura, como instrumento de desenvolvimento pessoal e social. Para a autora, o hábito de leitura deve ser incorporado desde cedo na escolarização de crianças.

O capítulo 8, intitulado Rendimento Acadêmico e Processos Cognitivos: algumas mudanças no paradigma da avaliação, analisa as contribuições e alerta para a necessidade da criação de novos instrumentos que objetivem a avaliação psicoeducacional; o autor destaca ainda, que novas formas de avaliações acadêmicas devem ser encontradas.

A inteligência emocional foi abordada no texto proposto por José Maurício Haas Bueno e Ricardo
Primi, chamado Inteligência Emocional: definição do construto e instrumento de medida. Os autores procuraram discutir a perspectiva histórica das teorias da inteligência, a definição do construto inteligência emocional e os principais instrumentos desenvolvidos para avaliar a inteligência emocional.

Tereza Cristina Siqueira Cerqueira e Acácia Aparecida Angeli dos Santos, no capítulo As Possiblidades de Avaliação dos Estilos de Aprendizagem, analisaram alguns instrumentos de avaliação de estilos de aprendizagem: o de Schmeck, o de Grasha-Riechmann e o de Kolb.

Dando continuidade à discussão anterior, Isabel Cristina Dib Bariani, Fermino Fernandes Sisto e Acácia Aparecida Angeli dos Santos, descrevem dois estudos que objetivam avaliar estilos cognitivos, no texto intitulado Construção de um Instrumento de Avaliação de Estilos Cognitivos.

O $12^{\circ}$ capítulo é de autoria de Fermino F. Sisto e colaboradores e trata da construção de uma escala sobre satisfação escolar (ASE).

A Análise Funcional do Comportamento é o tema desenvolvido por Érica Maria Machado Santarém; a autora apresenta algumas tendências da análise funcional e chama a atenção para a importância do desenvolvimento de novas tecnologias.

O último capítulo da obra ficou sob a responsabilidade de Josiane de Freitas Tonelotto, que trabalha com A Problemática da Avaliação das Dificuldades de Atenção. O texto tem como objetivo revisar conceitualmente o termo atenção, destacando a avaliação das dificuldades, o contexto e a faixa etária mais adequados para a identificação precoce de quaisquer dificuldades.

A leitura deste livro é recomendada aos interessados no processo de avaliação psicológica, uma vez que oferece uma ampla discussão a respeito de contextos, métodos e referenciais teóricos, sendo sustentado por uma boa revisão da literatura. Sua linguagem é de fácil compreensão e a organização dos capítulos, bastante coerente. Cabe ressaltar que manuscritos desta qualidade são necessários para a área de avaliação psicológica.

\section{Ana Paula Porto Noronha Universidade São Francisco - Itatiba/SP}

